\title{
Cyclophosphamide for salvage therapy of chronic graft-versus-host disease: a retrospective analysis
}

\author{
Matthias A. Fante ${ }^{1} \cdot$ Barbara Holler $^{1} \cdot$ Daniela Weber ${ }^{1} \cdot$ Klemens Angstwurm $^{2} \cdot$ Tobias Bergler $^{3} \cdot$ Ernst Holler $^{1}$. \\ Matthias Edinger ${ }^{1} \cdot$ Wolfgang Herr $^{1} \cdot$ Tobias Wertheimer $^{1} \cdot$ Daniel Wolff $^{1}$
}

Received: 9 February 2020 / Accepted: 20 July 2020 / Published online: 26 July 2020

(C) The Author(s) 2020

\begin{abstract}
We retrospectively analyzed the safety and efficacy of cyclophosphamide (cyclo) for salvage treatment of chronic graft-versushost disease (cGvHD) and cGvHD-associated (glomerulo-)nephritis at our center between 01/2010 and 11/2019. We identified 13 patients (pts) receiving cyclo for treatment of moderate (3/13) and severe (6/13) steroid-refractory cGvHD, cGvHD-associated (glomerulo-)nephritis (3/13), or vasculitis-like CNS manifestation of cGvHD (1/13). Cyclo was started on median day 509 (range 42-8193) after cGvHD onset; the median duration of application was 153 days (range 14-486) with 2/13 currently continuing treatment. The National Institute of Health organ grading and the intensity of immunosuppression (IS) were assessed at cyclo start and repeated after 3, 6, and 12 months. Response assessment was stopped at the start of any additional new IS. The median time of follow up was 407 days (range 86-1534). Best response was 1/13 CR, 6/13 PR, 4/13 SD, 1/13 MR, and 1/13 PD (ORR 54\%). Significant and durable response was observed especially in cGvHD-associated (glomerulo-)nephritis (3/3). Infectious complications > CTCAE grade III were observed in 3/12 pts. During cyclo therapy, none of the pts suffered from recurrence of underlying malignancy. Overall, cyclo was relatively well tolerated and showed responses in heavily pretreated patients but requires further evaluation within clinical trials.
\end{abstract}

Keywords Chronic graft versus host disease $\cdot$ Vasculitis-like cGvHD manifestation $\cdot$ Salvage therapy $\cdot$ Cyclophosphamide

\section{Introduction}

The main benefit of allogeneic stem cell transplantation (alloHSCT) is a sustained graft-versus-malignancy effect, unfortunately often accompanied by graft-versus-host disease (GvHD) significantly contributing to non-relapse mortality and reduced quality of life [1,2]. Chronic GvHD (cGvHD) is a multistep, host-reactive complication that occurs in up to $70 \%$ of patients $[3,4]$. The underlying pathophysiology is still

Tobias Wertheimer and Daniel Wolff contributed equally to this work.

Matthias A. Fante

matthias.fante@ukr.de

1 Department of Hematology and Oncology, Internal Medicine III, University Hospital Regensburg, Franz-Josef-Strauß-Allee 11, 93053 Regensburg, Germany

2 Department of Neurology, University Hospital Regensburg, Regensburg, Germany

3 Department of Nephrology, University Hospital Regensburg, Regensburg, Germany not fully understood, but new insights into the complex interplay of damage patterns, alterations in antigen presentation, dysregulation of B- and T-lymphocytes as well as interleukins promoting chronic inflammation, and tissue fibrosis recently advanced the field $[5,6]$.

Once diagnosed and staged by the current NIH consensus criteria, the standard first-line treatment of cGvHD consists of glucocorticoids with or without calcineurin inhibitors (CNIs) $[7,8]$. However, about $50 \%$ of patients do not respond to firstline treatment and the second-line therapies are based mainly on phase II trials or retrospective analyses [9] and are applied off-label, except the recently FDA-approved drug ibrutinib. In the last decade, promising treatment strategies involve immunomodulating therapies (e.g., mTOR inhibitors, photopheresis) as well as $B$ and $T$ cell targeting agents (e.g., ruxolitinib, ibrutinib, rituximab) and further substances are under investigation [10-13].

Since its development in the late 1950s, cyclophosphamide (cyclo), a member of the nitrogen mustard family, is commonly applied in the therapy of a wide array of malignancies (including breast, lymphoid, and pediatric neoplasia) and as an essential component of conditioning regimens in bone marrow and 
peripheral blood stem cell transplantation (BMT/PBSCT) [14-17]. Furthermore, cyclo exerts immunosuppressive effects and is routinely used for treatment of autoimmune conditions (e.g., small vessel vasculitis, systemic lupus erythematosus) $[18,19]$ and prophylaxis of GvHD in the haploidentical donor transplantation setting $[20,21]$. For the treatment of cGvHD, anecdotal reports were published for the use of cyclo [22, 23]. Upon oral or intravenous administration, the prodrug cyclo undergoes an enzymatical activation by the hepatic cytochrome P450 system followed by a cytoplasmatic rearrangement process ( $\beta$-elimination) to its active metabolite phosphoramide mustard causing inter- and intrastrand DNA cross-links [24].

As no data besides the anecdotal reports exist, we retrospectively analyzed the efficacy and safety of all patients receiving cyclo for treatment of cGvHD between 2010 and 2019 at the University Hospital Regensburg.

\section{Patients and methods}

\section{Patients}

All patients treated with cyclo for cGvHD at the transplantation program of the University Hospital Regensburg between 01/ 2010 and 11/2019 $(n=13)$ were included in the retrospective analysis approved by the institutional review board (no. 191585-104). The National Institute of Health (NIH) consensus criteria grading for cGvHD and the immunosuppressive regimen were assessed at the time of the first cyclo administration and repeated 3, 6, and 12 months of therapy as part of clinical routine during regular follow-up outpatient visits [25]. No other immunosuppressive agents were started within 4 weeks before start of cyclo and response assessment was stopped at the switch to any additional new immunosuppressive treatment line. Patients receiving cyclo as part of treatment for relapsed multiple myeloma after alloHSCT were excluded. Intention to treat was steroidrefractory cGvHD in nine patients, whereas three patients suffered from cGvHD-associated (glomerulo-)nephritis and one patient from vasculitis-like CNS manifestation of cGvHD.

\section{Response and event definition}

Response was defined as complete remission (CR) in case of resolution of all cGvHD manifestations. Partial remission (PR) described an improvement of at least one organ grade or in case of nephritis decreased proteinuria (mg protein/g creatinine) $>50 \%$ without an increase in creatinine levels $>$ $20 \%$. Mixed response (MR) was defined as complete or partial remission in at least one but progression in another organ site, whereas progressive disease (PD) meant a progression without any improvements. No change in organ grading or cerebral lesions was classified as stable disease (SD).
For assessment of infectious complications, the common terminology criteria for adverse events version 5.0 (CTCAE 5.0) were applied. Toxicities with a CTCAE grades I and II were not captured in the analysis.

\section{Results}

\section{Patient characteristics}

We identified and analyzed 13 patients (male $n=8$, female $n=5$ ) treated with cyclo between $01 / 2010$ and $11 / 2019$ for cGvHD. Initial diagnoses leading to alloHSCT were myeloid disorders (acute myeloid leukemia (AML), myelodysplastic syndrome (MDS), myeloproliferative neoplasia (MPN)) in eight patients, whereas five patients suffered from lymphatic malignancies (multiple myeloma (MM), non-Hodgkin lymphoma (NHL)). All except one patient received a matched donor graft of related $(n=7)$ or unrelated $(n=6)$ donors. The predominant graft source was peripheral blood stem cells (PBSC, 12/13), while one patient received a bone marrow graft. GvHD prophylaxis consisted of a calcineurin inhibitor (ciclosporin A (CsA) or tacrolimus) and methotrexate (MTX) with $(n=8)$ or without ATG $(n=4)$. Only one patient received a prophylaxis with CsA and mycophenolate mofetil (MMF). Ten of 13 patients developed acute GvHD (aGvHD) on median day 27 (range: 13-63, no assessment in one patient) postalloHSCT with a maximum grade (by Glucksberg criteria) of 2 or higher in $46 \%$. Patient characteristics and history of aGvHD are summarized in Table 1.

Onset of cGvHD was quiescent in eight, de novo in three, and progressive in two patients. The onset of cGvHD was observed on median day 202 (range: 84-571) upon alloHSCT; thrombocyte count at onset was $<100 / \mathrm{nl}$ in five patients (no assessment available in one patient). A median of three (range 1-6) organs or sites were involved at start of treatment: eyes (6/13), lung (6/13), skin (4/13), fascia and joints (4/13), mouth (3/13), kidney (3/13), liver (1/13), genital (1/13), gastrointestinal (1/13), and CNS (1/13). Cyclo was started on median day 938 (range 2188282) after alloHSCT and on day 509 (range 42-8193) after cGvHD onset, respectively. Prior to cyclo, a median of 2 therapy lines $(0-8)$ had been administered. The individual patient's treatments and the respective indication for use of cyclophosphamide are listed in Table 2. At the start of cyclo therapy, GvHD grading was moderate in three and severe in six patients. Three patients suffered from GvHD-associated (glomerulo-)nephritis with proteinuria and one patient from ischemic CNS lesions with focal neurologic deficits due to vasculitis-like cerebral cGvHD manifestation. Twelve patients received a continuous oral dose of $50 \mathrm{mg} /$ day $(n=6)$ or every $2-3$ days due to impaired blood counts $(n=6)$, whereas one patient was treated with a pulse therapy (initial 4 applications fortnightly, following 3 applications monthly, each $7.5 \mathrm{mg} / \mathrm{kg}$ intravenously). Steroid dose at 
Table 1 Patient characteristics

\begin{tabular}{|c|c|}
\hline & Value (\%) \\
\hline Patients, $n(\%)$ & $13(100)$ \\
\hline Male, $n(\%)$ & $5(39)$ \\
\hline Female, $n(\%)$ & $8(61)$ \\
\hline Age at transplantation, median (range) & $53(26-63)$ \\
\hline Age at start of cyclo therapy, median (range) & $55(28-67)$ \\
\hline \multicolumn{2}{|l|}{ Diagnosis, $n(\%)$} \\
\hline AML & $3(23)$ \\
\hline MDS & $2(15)$ \\
\hline NHL & $3(23)$ \\
\hline Multiple myeloma & $2(15)$ \\
\hline MPN & $3(23)$ \\
\hline \multicolumn{2}{|l|}{ Conditioning regime, $n(\%)$} \\
\hline FBM & $3(23)$ \\
\hline FTM & $3(23)$ \\
\hline Treosulfan/fludarabin & $3(23)$ \\
\hline Others & $4(31)$ \\
\hline \multicolumn{2}{|l|}{ Donor type, $n(\%)$} \\
\hline HLA-matched unrelated & $5(38)$ \\
\hline HLA-matched related & $7(54)$ \\
\hline HLA-mismatched unrelated & $1(8)$ \\
\hline \multicolumn{2}{|l|}{ Gender mismatch, $n(\%)$} \\
\hline Yes & $7(54)$ \\
\hline No & $6(46)$ \\
\hline \multicolumn{2}{|l|}{ Graft source, $n(\%)$} \\
\hline PBSC & $12(92)$ \\
\hline BM & $1(8)$ \\
\hline \multicolumn{2}{|l|}{ GvHD prophylaxis, $n(\%)$} \\
\hline ATG, CsA, MTX & $8(61)$ \\
\hline CsA, MMF & $1(8)$ \\
\hline CsA, MTX & $3(23)$ \\
\hline Tacrolimus, MTX & $1(8)$ \\
\hline \multicolumn{2}{|l|}{ History of a GvHD, $n(\%)$} \\
\hline Grade $0-\mathrm{I}$ & $7(54)$ \\
\hline Grade II-IV & $6(46)$ \\
\hline aGvHD onset, median (range) & $27(13-63)$ \\
\hline
\end{tabular}

$n$ number of patients, $A M L$ acute myeloid leukemia, $M D S$ myelodysplastic syndrome, $N H L$ non-Hodgkin lymphoma, $M P N$ myeloproliferative neoplasia, FBM fludarabine/busulfan/melphalan, FTM fludarabine/treosulfan/melphalan, HLA human leukocyte antigen, $P B S C$ peripheral blood stem cell, $B M$ bone marrow, $A T G$ anti-thymocyte globulin, $C s A$ ciclosporin A, MTX methotrexate, $G v H D$ graft versus host disease, $a G v H D$ acute GvHD

start of cyclo treatment was in median $0.295 \mathrm{mg} / \mathrm{kg}$ (range: $0.11-$ $1.18 \mathrm{mg} / \mathrm{kg}$ ). The duration of cyclo therapy was median 153 days (range: 14 486), and therapy was still ongoing in two patients at the time of last assessment (date 11/30/2019). Median follow-up after treatment was 407 days (range: 86-1534). A more detailed overview is given in Table 3 .

\section{3-month follow-up}

The 3-month follow-up was reached by nine patients with one patient achieving complete remission and three patients partial remission resulting in an overall response rate (ORR) of $31 \%$. Because of a sustained and progressive renal improvement for longer than 6 months, one of these patients was classified as partial remission despite a $48.8 \%$ (instead of $50 \%$ ) decrease in proteinuria. In contrast, three patients had a stable disease and two further patients showed a progressive disease. New immunosuppressive medication was started in four cases precluding any response assessment. Of those, one patient received mesenchymal stem cells (MSCs) in a status of partial remission 1 month after cyclo start and three patients had aggravating cGvHD with pulmonary manifestations in two cases (Table 3). None of the patients suffered from relapse of the underlying malignancy; the failure-free survival (FFS) was $69 \%$ after 3 months. Within the first 3 months, immunosuppressants besides cyclo were reduced in four patients.

\section{6- and 12-month follow-up}

At 6 months after initiation of the cyclo treatment, one patient still had a complete remission and two patients showed partial remission, whereas one patient remained unresponsive. One additional patient developed progressive disease $(n=3)$ with new oral and aggravated ocular cGvHD. No further patient needed a new ISM (Table 3). After 6 months, ORR was $23 \%$ and FFS was $69 \%$.

At 12-month follow-up, a total of six patients received new ISM and three patients have not yet reached the point of time. Two patients still showed a partial remission, one patient had a stable disease and one patient had progressive disease, displaying an ORR of 15\% and an FFS of 54\% (Table 3).

\section{Cyclophosphamide in vasculitic CGvHD manifestations}

Cyclo is a commonly used treatment option in vasculitis. Therefore, we analyzed patients receiving cyclo due to cGvHD-associated vessel diseases (cGvHD-associated nephritis, cGvHD-related PML). Three patients showed a cGvHD-associated GN and nephritis, respectively, displayed by increased creatinine levels (median: $119 \mu \mathrm{mol} / 1$, range: $81-$ 225) and proteinuria (median: $2799 \mathrm{mg} / \mathrm{g}$ creatinine, range: 1669-3659). The subtypes were classified as membranous GN $(n=1)$ and focal segmental GN $(n=1)$ by biopsy and as tubulointerstitial nephritis by urine examination $(n=1)$. During the course of cyclo treatment, all patients showed a partial remission of proteinuria (mean of best reduction: $81.7 \%$ ) with concomitantly improved renal function within 3 months after first cyclo administration (Fig. 1). Of note, one patient required new ISM due to newly developed 


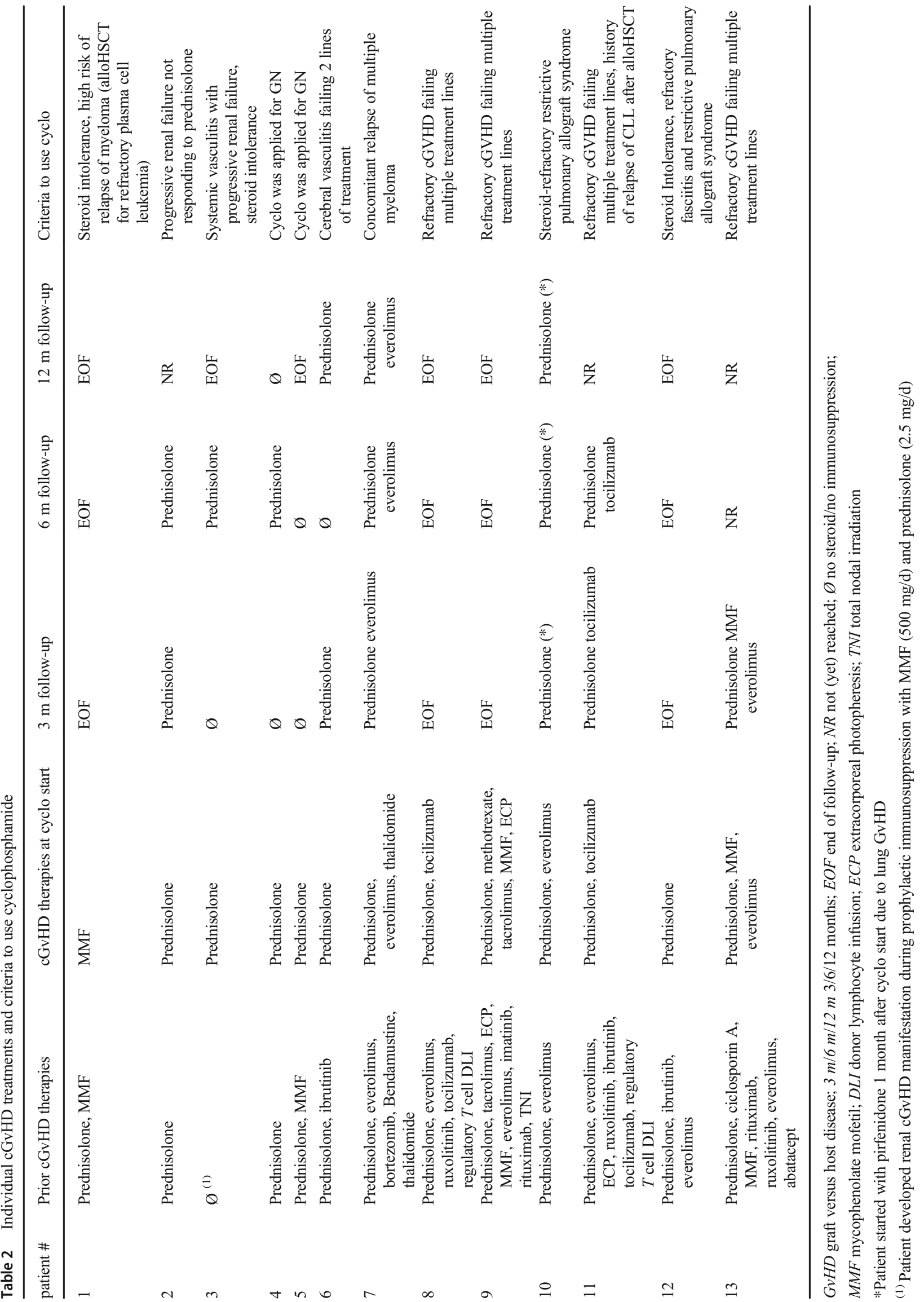




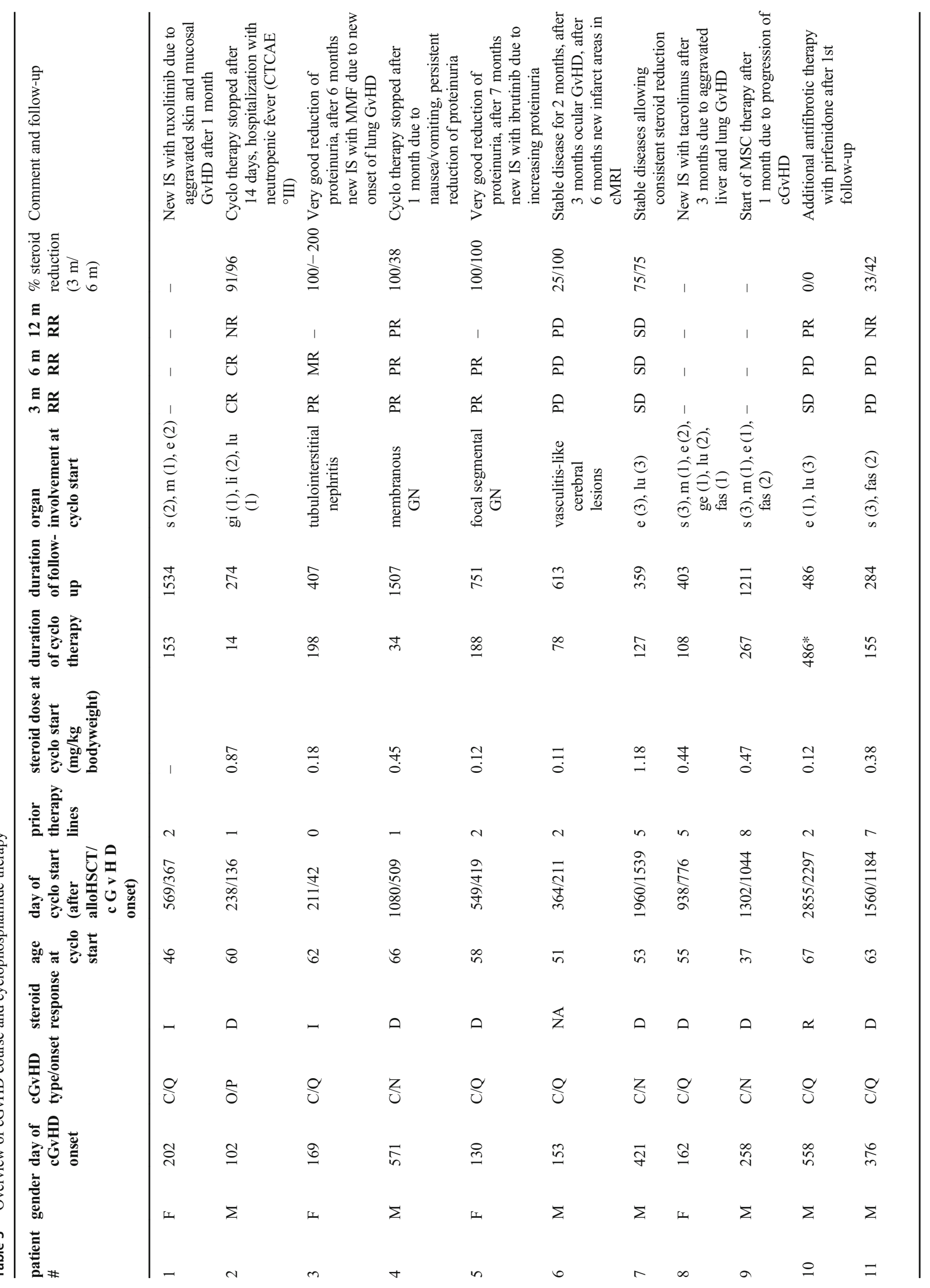




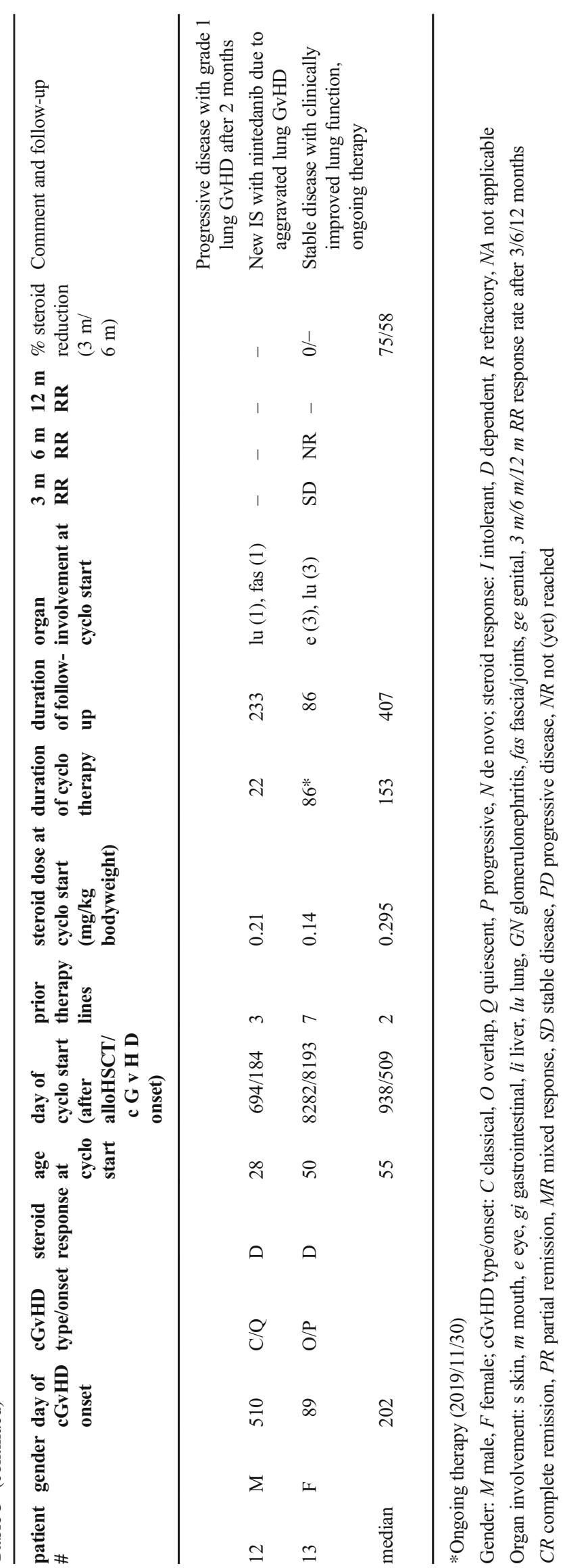


Fig. 1 a Time course of proteinuria in patients III (round), IV (square), and V (triangle) after start of cyclo therapy. A distinct and durable reduction of proteinuria is shown in patients within 3 months. After 6 months follow-up is discontinued in patients III and V due to new ISM. Dashed line marks nephrotic proteinuria of $2 \mathrm{~g} / \mathrm{g}$ creatinine. b Serum creatinine levels of patients III-V during the first 3 months of cyclo administration. In patient III, creatinine levels increase acutely within 9 days and afterward drop distinctly. Patients IV and V show a stable creatinine level a

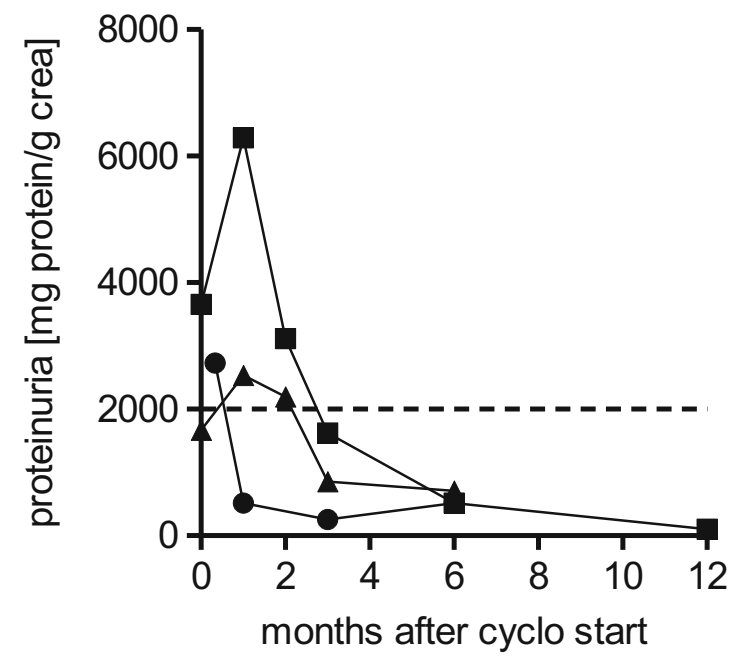

b

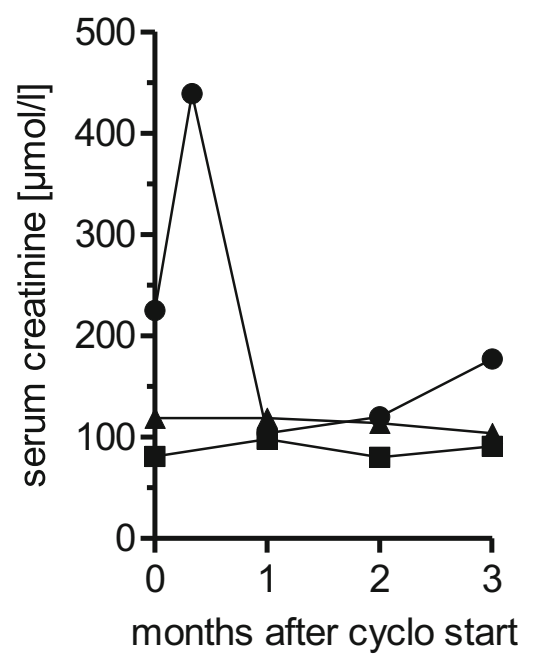

moderate lung GvHD during treatment and one patient showed increasing proteinuria 1 month after discontinuation of cyclo therapy. All patients suffering from renal manifestation of cGvHD received angiotensin-converting enzyme (ACE) inhibitors or angiotensin II receptor blockers (ARBs), respectively. However, treatment was started before cGvHD onset due to arterial hypertension in all patients.

The patient suffering from cGvHD-associated ischemic cerebral lesions showed only a short phase of stable disease. Due to clinically significant adverse events with headache, alopecia, arthritis, and nausea, cyclo had to be discontinued after 2 months. One month later, the patient developed ocular cGvHD; 3 months later, ischemic lesions progressed and immunosuppressive therapy with methotrexate was started. Thus, we considered the patient to be a non-responder.

\section{Infectious complications during and after cyclophosphamide therapy}

An early neutropenia was observed in two patients receiving cyclo orally after 1 and 4 weeks, respectively. Four patients were hospitalized (CTCAE grade III) due to an infection on median day 52 (range: 11-143) after start of cyclo treatment, of whom three suffered from respiratory symptoms and one from a urinary tract infection. None of the patients developed grade IV (intensive care unit) or V (death) infectious complications. The listed infections occurred during or immediately after cyclo treatment, and only one patient had meanwhile received further immunosuppressive treatment with mesenchymal stem cells. A correlation between response and infectious complications was not detectable, considering the low patient numbers.

\section{Steroid-sparing effect of cyclophosphamide}

As shown in Fig. 2, steroid dose of all patients reaching the follow-up was significantly reduced during the first 3 months of therapy by a median of 75\% (range 0-100\%). After 6 and 12 months, required steroid doses were increasing compared with the 3-month follow-up, but still reduced by 58 and $44 \%$ as compared with the initial dose. However, after 6 months, one patient received a tripled dose of steroids due to cGvHD progression, whereas all other patients had reduced or stable steroid need (Table 3).

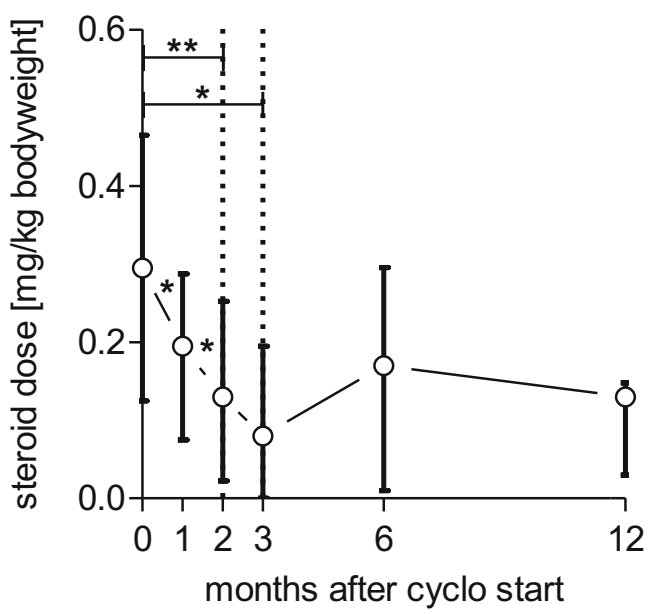

Fig. 2 Steroid dose per kg bodyweight within a 12 months follow-up period. A significant reduction is observed during the first 3 months, afterwards steroid need increases. $(P$ value $0.05>*>0.01>* *>0.005$, treatment induced changes are analyzed with Wilcoxon test, data are presented as median with interquartile range) 


\section{Predictive markers for response and safety of cyclophosphamide}

Cyclo poses an uncommon cGvHD therapy and a predictive marker supported selection of suitable patients simplifies the decision-making process. Moreover, the number of patients precludes any valid statistics. Patients achieving complete or partial remission were characterized by an advanced age (mean 61.5 vs 50 years), lower number of pre-cyclo treatments (mean 1 vs 4.6), no further non-steroid ISM at cyclo start (0 vs 1.3), a shorter period until cyclo treatment (mean 281 vs 1755 days), and a lower platelet count at cGvHD onset (mean 99 vs 173/nl). However, cyclo and steroid dose did not predict response. In contrast, patients developing adverse events (CTCAE $\geq$ III) during or after cyclo treatment were younger (mean 44.5 vs 57.6 years), showed a higher number of pre-cyclo treatment lines (mean 4.3 vs 3.1), increased nonsteroid ISM at cyclo start (mean 1.5 vs 0.7 ), and elevated steroid doses at cyclo start ( $0.69 \mathrm{vs} 0.22 \mathrm{mg} / \mathrm{kg}$ bodyweight). In our cohort, we did not find a dependency of the cyclo dose on adverse events.

\section{Discussion}

Steroid-refractory cGvHD poses a challenge for physicians due to the fact that empiric second-line treatments still show unsatisfactory overall responses ranging from 20 to $85 \%$ [26]. Clinical and pathophysiological similarities between cGvHD and autoimmune-mediated connective tissue diseases (e.g., systemic sclerosis, systemic lupus erythematosus) are described [27], and the application of therapeutics used in autoimmune diseases in cGvHD is an plausible strategy [28,29]. In our single-center retrospective analysis of patients treated with cyclo, we observed a moderate ORR of $31 \%$ after 3 months. This is in fact lower as compared with the reported response of the recently FDA-approved agent ibrutinib (67\%) [11]. Although cyclo represents a rather old second-line agent and has been applied mainly in prophylaxis of GvHD during the last decade, the relatively low response rate might be explained by the fact that the cohort consisted of heavily pretreated cGvHD patients having received a median of 2 prior treatment lines (range 0-8). Additionally, response to cyclo treatment substantially varied between involved organs and affected cGvHD sites.

Lung GvHD improved in $1 / 6$ patients, while $5 / 6$ patients showed stable disease, but three patients even developed new pulmonary involvement during therapy. Although it must be taken into account that lung involvement is mostly nonreversible and stabilization may already be a success [30], a significant proportion of patients progressed on cyclo indicating failure in a subset of patients. Cyclo has shown benefits in patients with fibrotic interstitial lung diseases [31], but can cause direct pulmonary toxicity by its active metabolites [32]. Therefore, it remains uncertain if failed response of cyclo in the context of lung GvHD is due to the underlying pathophysiology or caused by toxic side effects.

In contrast, all patients suffering from cGvHD-associated (glomerulo-)nephritis with extensive proteinuria responded after 3 months with durable improvement of renal function upon cyclo administration. This is underlined by the observation of relapsed proteinuria in one patient 4 weeks after discontinuation of cyclo therapy. Cyclo is well established for the treatment of glomerulonephritis (e.g., rapidly progressive GN, systemic lupus erythematosus associated nephritis), but most often applied as pulsed, intravenous therapy [33], which may be less well tolerated by alloHSCT patients due to hematotoxicity. As all but one patient analyzed received oral applications of cyclo, we cannot make any statements on the outcome concerning efficacy and adverse events of intravenous versus oral administration. Additionally, the oral doses varied between daily and two- to three-daily 50-mg application in our cohort. The best response (CR or PR) in the "high-dose" (daily oral or iv administration) versus "low-dose" (two- to three-daily administration) group showed similar efficiency ( $55 \mathrm{vs.} 50 \%$ ), however on costs of infectious complications $\geq$ CTCAE grade III, which only occurred in the "high-dose" group. With regard to predictive marker of response to cyclo, earlier treatment lines and a shorter interval between onset of symptoms and treatment of cGvHD have been repetitively associated with higher response rates and are most likely not cyclo specific.

The major concern in patients receiving continuous treatment with cyclo is the increased risk of infectious morbidity. Our cohort showed a substantial hospitalization rate of $31 \%$ due to infectious complications ( $75 \%$ pneumonia, $25 \%$ lower urinary tract infection); however, no patient needed intensive care and none of the patients died in the course of the cyclo therapy. Nonetheless, these data reflect the importance of a strict selection of potential cyclo recipients and a continuous surveillance of outpatients.

Of note, we observed a meaningful reduction of steroid dose by a median of $75 \%$ and $58 \%$ (Fig. 2) after 3 and 6 months, respectively, which had been even higher if not one single patient received a tripled dose due to cGvHD progress after 6 months. Therefore, cyclo may be considered steroid-sparing agent in cGvHD therapy and be particularly suited to treat cGvHD-associated nephropathy.

In conclusion, cyclophosphamide may be an effective treatment option in some but not all cGvHD manifestations with a high response rate in GvHD-associated (glomerulo-)nephritis. To gain more experience, further evaluations in larger cohorts are necessary.

Funding information Open Access funding provided by Projekt DEAL. This work was funded by the German Research Foundation, collaborative research center 221, individual project B10 (Daniel Wolff). 


\section{Compliance with ethical standards}

Conflict of interest M Fante has received a travel grant from Neovii. D Wolff has received honoraria from Mallinckrodt, Novartis, Takeda, MACO and Neovii. All other authors declare no conflicts of interest.

Ethical approval The retrospective analysis was approved by the institutional ethics committee of University Regensburg (\#19-1585-104; 11/ 2019) and in accordance with the Helsinki Declaration of 1975 , as revised in 2008. All the procedures being performed were part of the routine care.

Informed consent All patients have granted informed consent prior to inclusion.

Open Access This article is licensed under a Creative Commons Attribution 4.0 International License, which permits use, sharing, adaptation, distribution and reproduction in any medium or format, as long as you give appropriate credit to the original author(s) and the source, provide a link to the Creative Commons licence, and indicate if changes were made. The images or other third party material in this article are included in the article's Creative Commons licence, unless indicated otherwise in a credit line to the material. If material is not included in the article's Creative Commons licence and your intended use is not permitted by statutory regulation or exceeds the permitted use, you will need to obtain permission directly from the copyright holder. To view a copy of this licence, visit http://creativecommons.org/licenses/by/4.0/.

\section{References}

1. Pidala J, Kurland B, Chai X, Majhail N, Weisdorf DJ, Pavletic S, Cutler C, Jacobsohn D, Palmer J, Arai S, Jagasia M, Lee SJ (2011) Patient-reported quality of life is associated with severity of chronic graft-versus-host disease as measured by NIH criteria: report on baseline data from the chronic GVHD consortium. Blood 117(17):4651-4657. https://doi.org/10.1182/blood-2010-11319509

2. Fraser CJ, Bhatia S, Ness K, Carter A, Francisco L, Arora M, Parker P, Forman S, Weisdorf D, Gurney JG, Baker KS (2006) Impact of chronic graft-versus-host disease on the health status of hematopoietic cell transplantation survivors: a report from the bone marrow transplant survivor study. Blood 108(8):2867-2873. https://doi.org/ 10.1182/blood-2006-02-003954

3. Arai S, Arora M, Wang T, Spellman SR, He W, Couriel DR, Urbano-Ispizua A, Cutler CS, Bacigalupo AA, Battiwalla M, Flowers ME, Juckett MB, Lee SJ, Loren AW, Klumpp TR, Prockup SE, Ringdén OT, Savani BN, Socié G, Schultz KR, Spitzer T, Teshima T, Bredeson CN, Jacobsohn DA, Hayashi RJ, Drobyski WR, Frangoul HA, Akpek G, Ho VT, Lewis VA, Gale RP, Koreth J, Chao NJ, Aljurf MD, Cooper BW, Laughlin MJ, Hsu JW, Hematti P, Verdonck LF, Solh MM, Norkin M, Reddy V, Martino R, Gadalla S, Goldberg JD, McCarthy P, Pérez-Simón JA, Khera N, Lewis ID, Atsuta Y, Olsson RF, Saber W, Waller EK, Blaise D, Pidala JA, Martin PJ, Satwani P, Bornhäuser M, Inamoto Y, Weisdorf DJ, Horowitz MM, Pavletic SZ, Graft-vsHost Disease Working Committee of the CIBMTR (2015) Increasing incidence of chronic graft-versus-host disease in allogeneic transplantation: a report from the Center for International Blood and Marrow Transplant Research. Biol Blood Marrow Transplant 21(2):266-274. https://doi.org/10.1016/j.bbmt.2014. 10.021

4. Arora M, Cutler CS, Jagasia MH, Pidala J, Chai X, Martin PJ, Flowers MED, Inamoto Y, Chen GL, Wood WA, Khera N,
Palmer J, Duong H, Arai S, Mayer S, Pusic I, Lee SJ (2016) Late acute and chronic graft-versus-host disease after allogeneic hematopoietic cell transplantation. Biol Blood Marrow Transplant 22(3): 449-455. https://doi.org/10.1016/j.bbmt.2015.10.018

5. Zeiser R, Blazar BR (2017) Pathophysiology of chronic graftversus-host disease and therapeutic targets. N Engl J Med 377(26):2565-2579. https://doi.org/10.1056/NEJMra1703472

6. Cooke KR, Luznik L, Sarantopoulos S, Hakim FT, Jagasia M, Fowler DH, van den Brink MRM, Hansen JA, Parkman R, Miklos DB, Martin PJ, Paczesny S, Vogelsang G, Pavletic S, Ritz J, Schultz KR, Blazar BR (2017) The biology of chronic graftversus-host disease: a task force report from the National Institutes of Health Consensus Development Project on criteria for clinical trials in chronic graft-versus-host disease. Biol Blood Marrow Transplant 23(2):211-234. https://doi.org/10.1016/j.bbmt. 2016.09.023

7. Jagasia MH, Greinix HT, Arora M et al (2015) National Institutes of Health Consensus Development Project on criteria for clinical trials in chronic graft-versus-host disease: I. the 2014 diagnosis and staging working group report. Biol Blood Marrow Transplant 21(3): 389-401.e1. https://doi.org/10.1016/j.bbmt.2014.12.001

8. Wolff D, Gerbitz A, Ayuk F, Kiani A, Hildebrandt GC, Vogelsang GB, Elad S, Lawitschka A, Socie G, Pavletic SZ, Holler E, Greinix H (2010) Consensus conference on clinical practice in chronic graft-versus-host disease (GVHD): first-line and topical treatment of chronic GVHD. Biol Blood Marrow Transplant 16(12):16111628. https://doi.org/10.1016/j.bbmt.2010.06.015

9. Wolff D, Schleuning M, von Harsdorf S, Bacher U, Gerbitz A, Stadler M, Ayuk F, Kiani A, Schwerdtfeger R, Vogelsang GB, Kobbe G, Gramatzki M, Lawitschka A, Mohty M, Pavletic SZ, Greinix H, Holler E (2011) Consensus conference on clinical practice in chronic GVHD: second-line treatment of chronic graftversus-host disease. Biol Blood Marrow Transplant 17(1):1-17. https://doi.org/10.1016/j.bbmt.2010.05.011

10. Greinix HT, Worel N, Just U, Knobler R (2014) Extracorporeal photopheresis in acute and chronic graft-versus-host disease. Transfus Apher Sci 50(3):349-357. https://doi.org/10.1016/j. transci.2014.04.005

11. Miklos D, Cutler CS, Arora M, Waller EK, Jagasia M, Pusic I, Flowers ME, Logan AC, Nakamura R, Blazar BR, Li Y, Chang S, Lal I, Dubovsky J, James DF, Styles L, Jaglowski S (2017) Ibrutinib for chronic graft-versus-host disease after failure of prior therapy. Blood 130(21):2243-2250. https://doi.org/10.1182/blood2017-07-793786

12. Zeiser R, Burchert A, Lengerke C, Verbeek M, Maas-Bauer K, Metzelder SK, Spoerl S, Ditschkowski M, Ecsedi M, Sockel K, Ayuk F, Ajib S, de Fontbrune FS, Na IK, Penter L, Holtick U, Wolf D, Schuler E, Meyer E, Apostolova P, Bertz H, Marks R, Lübbert M, Wäsch R, Scheid C, Stölzel F, Ordemann R, Bug G, Kobbe G, Negrin R, Brune M, Spyridonidis A, Schmitt-Gräff A, van der Velden W, Huls G, Mielke S, Grigoleit GU, Kuball J, Flynn R, Ihorst G, du J, Blazar BR, Arnold R, Kröger N, Passweg J, Halter J, Socié G, Beelen D, Peschel C, Neubauer A, Finke J, Duyster J, von Bubnoff N (2015) Ruxolitinib in corticosteroid-refractory graft-versus-host disease after allogeneic stem cell transplantation: a multicenter survey. Leukemia 29(10):2062-2068. https://doi.org/ 10.1038/leu.2015.212

13. Cutler C, Miklos D, Kim HT, Treister N, Woo SB, Bienfang D, Klickstein LB, Levin J, Miller K, Reynolds C, Macdonell R, Pasek M, Lee SJ, Ho V, Soiffer R, Antin JH, Ritz J, Alyea E (2006) Rituximab for steroid-refractory chronic graft-versus-host disease. Blood 108(2):756-762. https://doi.org/10.1182/blood-2006-010233

14. Emadi A, Jones RJ, Brodsky RA (2009) Cyclophosphamide and cancer: golden anniversary. Nat Rev Clin Oncol 6(11):638-647. https://doi.org/10.1038/nrclinonc.2009.146 
15. Mamounas EP, Bryant J, Lembersky B, Fehrenbacher L, Sedlacek SM, Fisher B, Wickerham DL, Yothers G, Soran A, Wolmark N (2005) Paclitaxel after doxorubicin plus cyclophosphamide as adjuvant chemotherapy for node-positive breast cancer: results from NSABP B-28. J Clin Oncol 23(16):3686-3696. https://doi.org/10. 1200/JCO.2005.10.517

16. Magrath I, Adde M, Shad A, Venzon D, Seibel N, Gootenberg J, Neely J, Arndt C, Nieder M, Jaffe E, Wittes RA, Horak ID (1996) Adults and children with small non-cleaved-cell lymphoma have a similar excellent outcome when treated with the same chemotherapy regimen. J Clin Oncol 14(3):925-934. https://doi.org/10.1200/ JCO.1996.14.3.925

17. Patel SS, Rybicki L, Pohlman B, Bolwell B, Gerds AT, Hamilton BK, Hanna R, Kalaycio M, Majhail NS, Sobecks R (2019) Comparative effectiveness of busulfan/cyclophosphamide versus busulfan/fludarabine myeloablative conditioning for allogeneic hematopoietic cell transplantation in acute myeloid leukemia and myelodysplastic syndrome. Hematol Oncol Stem Cell Ther. https://doi.org/10.1016/j.hemonc.2019.09.002

18. Harper L, Morgan MD, Walsh M, Hoglund P, Westman K, Flossmann O, Tesar V, Vanhille P, de Groot K, Luqmani R, Flores-Suarez LF, Watts R, Pusey C, Bruchfeld A, Rasmussen N, Blockmans D, Savage CO, Jayne D, EUVAS investigators (2012) Pulse versus daily oral cyclophosphamide for induction of remission in ANCA-associated vasculitis: long-term follow-up. Ann Rheum Dis 71(6):955-960. https://doi.org/10.1136/annrheumdis2011-200477

19. Joy MS, La M, Wang J et al (2012) Cyclophosphamide and 4hydroxycyclophosphamide pharmacokinetics in patients with glomerulonephritis secondary to lupus and small vessel vasculitis. Br J Clin Pharmacol 74(3):445-455. https://doi.org/10.1111/j.13652125.2012.04223.x

20. Raj K, Pagliuca A, Bradstock K, Noriega V, Potter V, Streetly M, Mclornan D, Kazmi M, Marsh J, Kwan J, Huang G, Getzendaner L, Lee S, Guthrie KA, Mufti GJ, O’Donnell P (2014) Peripheral blood hematopoietic stem cells for transplantation of hematological diseases from related, haploidentical donors after reduced-intensity conditioning. Biol Blood Marrow Transplant 20(6):890-895. https://doi.org/10.1016/j.bbmt.2014.03.003

21. Luznik L, Bolaños-Meade J, Zahurak M, Chen AR, Smith BD, Brodsky R, Huff CA, Borrello I, Matsui W, Powell JD, Kasamon Y, Goodman SN, Hess A, Levitsky HI, Ambinder RF, Jones RJ, Fuchs EJ (2010) High-dose cyclophosphamide as single-agent, short-course prophylaxis of graft-versus-host disease. Blood 115(16):3224-3230. https://doi.org/10.1182/blood-2009-11251595

22. Mayer J, Krejcí M, Doubek M et al (2005) Pulse cyclophosphamide for corticosteroid-refractory graft-versus-host disease. Bone
Marrow Transplant 35(7):699-705. https://doi.org/10.1038/sj.bmt. 1704829

23. Pusic I, Pavletic SZ, Kessinger A, Tarantolo SR, Bishop MR (2002) Pseudoautologous blood stem cell transplantation for refractory chronic graft-versus-host disease. Bone Marrow Transplant 29(8): 709-710. https://doi.org/10.1038/sj.bmt. 1703550

24. Boddy AV, Yule SM (2000) Metabolism and pharmacokinetics of oxazaphosphorines. Clin Pharmacokinet 38(4):291-304. https:// doi.org/10.2165/00003088-200038040-00001

25. Schoemans HM, Lee SJ, Ferrara JL et al (2018) EBMT-NIHCIBMTR task force position statement on standardized terminology \& guidance for graft-versus-host disease assessment. Bone Marrow Transplant 53(11):1401-1415. https://doi.org/10.1038/ s41409-018-0204-7

26. Flowers MED, Martin PJ (2015) How we treat chronic graft-versushost disease. Blood 125(4):606-615. https://doi.org/10.1182/ blood-2014-08-551994

27. Tyndall A, Dazzi F (2008) Chronic GVHD as an autoimmune disease. Best Pract Res Clin Haematol 21(2):281-289. https://doi.org/ 10.1016/j.beha.2008.03.003

28. Fernández-Codina A, Walker KM, Pope JE (2018) Treatment algorithms for systemic sclerosis according to experts. Arthritis Rheumatol 70(11):1820-1828. https://doi.org/10.1002/art.40560

29. Davis LS, Reimold AM (2017) Research and therapeuticstraditional and emerging therapies in systemic lupus erythematosus. Rheumatology (Oxford) 56(suppl_1):i100-i113. https://doi. org/10.1093/rheumatology/kew417

30. Hildebrandt GC, Fazekas T, Lawitschka A, Bertz H, Greinix H, Halter J, Pavletic SZ, Holler E, Wolff D (2011) Diagnosis and treatment of pulmonary chronic GVHD: report from the consensus conference on clinical practice in chronic GVHD. Bone Marrow Transplant 46(10):1283-1295. https://doi.org/10.1038/bmt.2011. 35

31. Schupp JC, Köhler T, Müller-Quernheim J (2016) Usefulness of cyclophosphamide pulse therapy in interstitial lung diseases. Respiration 91(4):296-301. https://doi.org/10.1159/000445031

32. Patel JM (1990) Metabolism and pulmonary toxicity of cyclophosphamide. Pharmacol Ther 47(1):137-146. https://doi.org/10.1016/ 0163-7258(90)90049-8

33. Ponticelli C, Escoli R, Moroni G (2018) Does cyclophosphamide still play a role in glomerular diseases? Autoimmun Rev 17(10): 1022-1027. https://doi.org/10.1016/j.autrev.2018.04.007

Publisher's note Springer Nature remains neutral with regard to jurisdictional claims in published maps and institutional affiliations. 